\title{
О ПРОБЛЕМЕ ГОТОВНОСТИ ВЫСШИХ УЧЕБНЫХ ЗАВЕДЕНИЙ К РЕАЛИЗАЦИИ ПРОГРАММЫ «ПРИОРИТЕТ 2030»: РИСКИ И ЭКОНОМИЧЕСКИЕ ВОЗМОЖНОСТИ
}

\author{
(c) 2021 Николаева Елена Анатольевна \\ кандидат социологических наук, доцент кафедры иностранных языков \\ Российский экономический университет им. Г. В. Плеханова, Россия, Москва \\ E-mail: yoltash82@mail.ru \\ (c) 2021 Казимирова Ирина Сергеевна \\ кандидат филологических наук, доцент кафедры иностранных языков \\ Российский экономический университет им. Г. В.Плеханова», Россия, Москва \\ E-mail: irinacasimirova@yandex.ru \\ (C) 2021 Кузнецова Юлия Андреевна \\ кандидат экономических наук, доцент кафедры иностранных языков \\ Российский экономический университет им.Г.В. Плеханова», Россия, Москва \\ E-mail: yulia_success@mail.ru \\ (c) 2021 Панченко Екатерина Юрьевна \\ старший преподаватель кафедры иностранных языков \\ Российский экономический университет им.Г.В. Плеханова, Россия, Москва \\ E-mail: katya368@yandex.ru
}

Статья авторов затрагивает проблему готовности высших учебных заведений к реализации программы «Приоритет: 2030» в аспекте рисков и экономических возможностей. Объектом исследования выступает программа «Приоритет 2030», а предметом - высшие учебные заведения Российской Федерации в аспекте рисков и экономических возможностей за счет присоединения к программе. Теоретическое значение исследования заключено в развитии теории рисков. Также теоретическое значение исследования обозначается расширением возможности взаимодействия различных образовательных институтов на федеральном уровне. Практическое и прикладное значение исследования заключены в выявлении и анализе экономических возможностей высших учебных заведений от реализации программы «Приоритет 2030». Полученные результаты могут быть использованы на практике для решения широкого круга задач, включая риск-менеджмент, экономику и систему высшего образования.

Ключевые слова: проблема, готовность, высшее учебное заведение, программа, реализация, риски, экономические возможности.

Федеральные программы в сфере образования являются одним из наиболее эффективных инструментов в развитии научного сектора в Российской Федерации, значительно увеличивая его возможности (экономические, социальные и информационные) в будущем [3, 5].

Из совокупного множества актуальных программ, функционирующих на территории Российской Федерации в 2021 году, можно выделить «Приоритет 2030» [8] - комплексную научную программу, предназначенную для всесторонней поддержки более ста высших учебных заведений, прошедших конкурсный отбор.

В рамках данной программы высшие учеб- ные заведения $[1,4]$ в Российской Федерации, отобранные для участия, получат не только значительное и, вероятно, регулярное финансирование (например, в рамках реализации грантов), но и возможность реализовать свой потенциал на научной мировой арене.

Оцененная на основе анализа ряда источников $[6,7,8]$ интегральная готовность (организационная, информационная, юридическая и прочее) высших учебных заведений в Российской Федерации к реализации обозначенной программы на начало 2021 года (с формированием прогноза на начало 2022 года) приведена на рисунке 1. 
Из рисунка 1 можно увидеть, что интегральный уровень готовности высших учебных заведений в Российской Федерации к реализации анализируемой программы не превысил 60 процентов. В частности, на начало 2021 года значение показателя готовности равнялось 53,8 процента из 100 процентов, а по прогнозам на начало 2022 года составит порядка 55,9 процента.

В целом готовность высших учебных заведений в Российской Федерации к реализации федеральной программы с учетом перспективы на начало 2022 года можно оценить как среднюю.

В рамках данной публикации были выявлены и проанализированы различные виды рисков [2, с. 51], определяющие проблему готовности высших учебных заведений к реализации программы «Приоритет 2030» на 2022-2030 годы (таблица 1).
Значимость выявленных рисков, определяющих проблему готовности высших учебных заведений к реализации программы «Приоритет 2030» приведена на рисунке 2.

Из рисунка 2 видно, что более половины по уровню значимости (порядка 57,5 процентов из 100,0 возможных) из рассматриваемых рисков приходится на методическую и информационную составляющие.

Именно поэтому данным аспектам деятельности высших учебных заведений Российской Федерации в будущем необходимо уделить максимум внимания.

Говоря о перспективах реализации анализируемой программы высшими учебными заведениями в Российской Федерации в рамках данного исследования, остановимся лишь на их экономической составляющей.

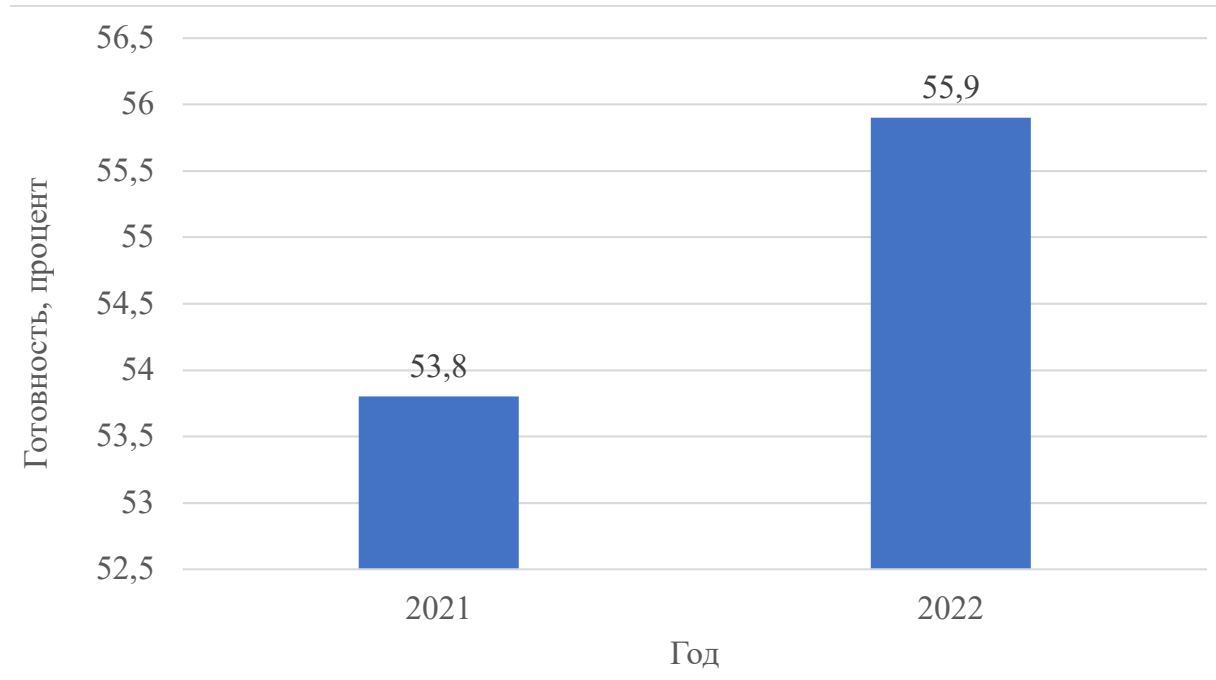

Pис. 1. Оцененная на основе анализа ряда источников интегральная готовность высших учебных заведений в Российской Федерации к реализации программы «Приоритет 2030» на начало 2021 года $[6,7,8]$

Таблица 1. Характеристика выявленных рисков, определяющих проблему готовности высших учебных заведений Российской Федерации к реализации программы «Приоритет 2030»

\begin{tabular}{|l|l|}
\hline \multicolumn{1}{|c|}{$\begin{array}{l}\text { Наименование } \\
\text { риска }\end{array}$} & \multicolumn{1}{c|}{ Характеристика риска } \\
\hline $\begin{array}{l}\text { Методические } \\
\text { риски }\end{array}$ & $\begin{array}{l}\text { Характеризуют готовность высших учебных заведений в Российской Федерации к реа- } \\
\text { лизации программы в методической плоскости }\end{array}$ \\
\hline $\begin{array}{l}\text { Информационные } \\
\text { риски }\end{array}$ & $\begin{array}{l}\text { Характеризуют готовность высших учебных заведений в Российской Федерации к реа- } \\
\text { лизации программы в информационной плоскости }\end{array}$ \\
\hline $\begin{array}{l}\text { Управленческие } \\
\text { риски }\end{array}$ & $\begin{array}{l}\text { Характеризуют готовность высших учебных заведений в Российской Федерации к реа- } \\
\text { лизации программы в плоскости управления (в том числе персоналом) }\end{array}$ \\
\hline Правовые риски & $\begin{array}{l}\text { Характеризуют готовность высших учебных заведений в Российской Федерации к реа- } \\
\text { лизации программы в правовой плоскости }\end{array}$ \\
\hline Прочие риски & $\begin{array}{l}\text { Характеризуют готовность высших учебных заведений в Российской Федерации к реа- } \\
\text { лизации программы в прочих плоскостях }\end{array}$ \\
\hline
\end{tabular}




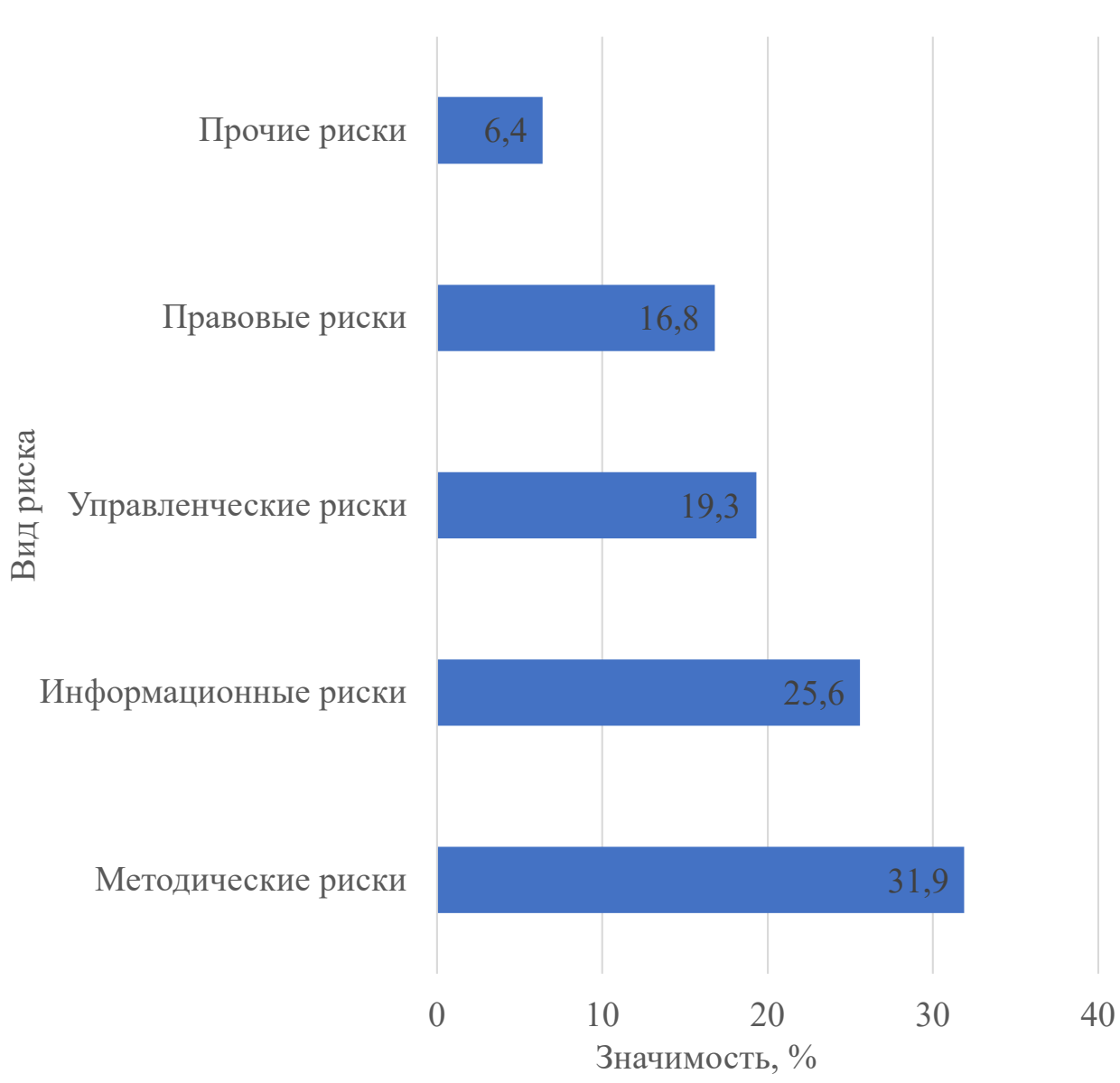

Puc. 2. Значимость выявленных рисков, определяющих проблему готовности высших учебных заведений к реализации программы «Приоритет 2030» на начало 2021 года Источник: составлено авторами

Выявленные экономические возможности высших учебных заведений в Российской Федерации в результате участия в программе «Приоритет 2030» на 2022-2030 годы приведены ниже в таблице 2.

По таблице 2 необходимо пояснить, что субсидированное финансирование грантов высших учебных заведений на период до 2030 года возможно лишь в случае достижения заявленных ими значений по ключевым показателям эффективности во всех анализируемых периодах. В противном случае финансирование грантов по программе «Приоритет 2030» может быть приостановлено, а неиспользованный остаток финансирования у высшего учебного заведения изъят.

Таким образом, можно отметить, что в Рос- сийской Федерации проблема готовности высших учебных заведений к реализации программы «Приоритет 2030» на начало 2021 года может быть оценена как средняя.

Риски, с которыми может столкнуться высшее учебное заведение в процессе реализации программы в 2022-2030 годах объединены в пять укрупненных групп (методические, информационные, управленческие, правовые, прочие риски), наиболее значимыми из которых являются первые две.

Экономические возможности высших учебных заведений в результате участия в реализации обозначенной программы будут заключаться в разовом и систематическом получении субсидий на совокупность грантов. 


\section{Библиографический список}

1. Гаркуша В.Н. Актуальные аспекты, проблемы и тенденции высшего образования / В.Н. Гаркуша / Информация-коммуникация-общество - Санкт-Петербург: Изд-во: Санкт-Петербургский государственный электротехнический университет «ЛЭТИ» им. В. И. Ульянова (Ленина), 2020. - № 1. - С. 27-31.

2. Долгова Е.Г., Казимирова И.С. и др. К вопросу развития глобальных (транснациональных) университетов в проекции перспектив и рисков высшего образования в Российской Федерации / Е. Г.Долгова, И. С. Казимирова, Ю. А. Кузнецова, Е. А. Николаева / Экономические науки - Москва: Изд-во: «ООО «24 Принт», 2021. - № 2. - С. 49-52.

3. Понизовкина И. Ф. Цифровизация высшего образования: перспективы и риски / И. Ф. Понизовкина / Право и практика - Москва: Изд-во: АНО «Научно-исследовательский институт истории, экономики и права», 2020. - № 1. - C. 194-202.

4. Чернова О.А. Проблемы развития цифровых процессов в высшем образовании: вызовы удаленного обучения / О.А. Чернова / Экономика образования - Москва: Изд-во: Частное учреждение «Издательство АЭО», 2020. - № 4. - C. 42-50.

5. Чирун С.Н. Высшее образование в современной России: проблемы и противоречия реализации образовательной политики / С.Н.Чирун / Вестник общественных и гуманитарных наук - Кемерово: Изд-во: федеральное государственное бюджетное образовательное учреждение высшего образования «Кемеровский государственный медицинский университет» Министерства здравоохранения Российской Федерации, 2020. - № 3. - C. 23-30.

6. Компания «Сбер Решения» [Электронный ресурс]: Аналитические обзоры - Официальный сайт компании «Сбер Решения», 2021. - Режим доступа: https://sber-solutions.ru/

7. Компания «Финансовый и организационный консалтинг» [Электронный ресурс]: Аналитические обзоры - Официальный сайт компании «Финансовый и организационный консалтинг», 2021. - Режим доступа: https://www.foconsult.ru/o-kompanii

8. Министерство науки и высшего образования Российской Федерации [Электронный ресурс]: Программа «Приоритет-2030» - Официальный сайт Министерства науки и высшего образования Российской Федерации, 2021. - Режим доступа: https://minobrnauki.gov.ru/ 